\title{
Frequency of Otorhinolaryngologies' Manifestations in Patients with Pulmonary Tuberculosis
}

\section{Frequência de Manifestaçôes Otorrinolaringológicas em Pacientes Portadores de Tuberculose Pulmonar}

\author{
Renato Telles de Sousa*, Maria Francisca Siqueira Briglia**, Luiz Carlos Nadaf de Lima***, \\ Rafael Siqueira de Carvalbo****, Livio Martins Teixeira*****, \\ Alexandre Herculanno Ribera Marcião****.
}

\footnotetext{
* Masters. Associate Professor, School of Medicine, Federal University of Amazonas and Chief Resident of Otorhinolaryngology, University Hospital Getulio Vargas. ** Masters. Associate Professor, School of Medicine, Federal University of Amazonas.

**** Master. ENT Care, University Hospital Getulio Vargas.

**** Resident of Otorhinolaryngology, University Hospital Getulio Vargas.

****** Physician. Chief Resident of Otorhinolaryngology, University Hospital Getulio Vargas.

Institution: Getulio Vargas University Hospital, Federal University of Amazonas. Manaus / AM - Brazil.

Mail Address: Rafael Siqueira de Carvalho - Rua Apurinã, 4 - Square January 14 - Manaus / AM - Brazil - Zip code: $69020-170$ - Telephone: (+55 92) 3621-6500 - E-mail: rsdecarvalho@hotmail.com

Article received in February 18, 2008. Article accepted in April 4, 2010.
}

\section{SUMMARY}

Introduction:

The tuberculosis continues being a world problem and in the last years had an increase in his incidence mainly by the growing number of patients with HIV. The tuberculosis has like an etiologic agent the Mycobacterium tuberculosis that possesses a period of latency generally prolonged between the initial infection and the illness. That illness can affect diverse organs and systems. M

Method: This study is descriptive, transversal and prospective. Within, patients diagnosed with pulmonary tuberculosis by the service of pneumologia of the outpatient clinic Araújo Lima of the Federal University of the Amazon (UFAM), in Manaus, between the period of July of 2005 and May of 2006 were submitted to otorhinolaryngological exam in search of manifestations of the illness.

Objectives: The main objective of the study was estimate the predominance of otorhinolaryngological manifestations in patients with tuberculosis and to describe the frequencies of the different manifestations.

Results: They were analyzed 15 cases of pulmonary tuberculosis confirmed by the baciloscopia, being 7 of the female sex and 8 of the male sex. The majority of the patients were young adults between the third and fourth decade of life $(46,7 \%)$. Only one of the patients had co-infection with the HIV virus.

Conclusion: The otorhinolaryngological affection by the tuberculosis was observed in 2 patients corresponding to $13.33 \%$ of the sample, being a patient with tubercular medium otitis and a patient with linfoadenopatia cervical.

Keywords: otorhinolaryngologies' manifestations, tuberculosis, frequency.

RESUMO

Introdução:

A tuberculose continua sendo um problema mundial e nos últimos anos teve um aumento na sua incidência principalmente pelo número crescente de pacientes com HIV. A tuberculose possui como agente etiológico o Mycobacterium tuberculosis que possui um período de latência geralmente prolongado entre a infecção inicial e a doença. Essa doença pode afetar diversos órgãos e sistemas.

Objetivo: O objetivo principal do estudo era estimar a prevalência de manifestações otorrinolaringológicas em pacientes portadores de tuberculose e descrever as frequências das diferentes manifestações.

Método: O estudo em questão é descritivo, transversal e prospectivo. Nele, pacientes diagnosticados com tuberculose pulmonar pelo serviço de pneumologia do ambulatório Araújo Lima da Universidade Federal do Amazonas (UFAM), em Manaus, entre o período de Julho de 2005 e Maio de 2006 foram submetidos a exame otorrinolaringológico em busca de manifestações da doença.

Resultados: $\quad$ Foram analisados 15 casos de tuberculose pulmonar confirmada pela baciloscopia, sendo 7 do sexo feminino e 8 do sexo masculino. A maioria dos pacientes eram adultos jovens entre a terceira e quarta década de vida (46,7\%). Apenas um dos pacientes possuía co-infecção com o vírus HIV.

Conclusão: O acometimento otorrinolaringológico pela tuberculose foi observado em 2 pacientes correspondendo a 13,33\% da amostra, sendo um paciente com otite média tuberculosa e um paciente com linfoadenopatia cervical.

Palavras-chave: manifestações otorrinolaringológicas, tuberculose, frequência. 


\section{INTRODUCTION}

Tuberculosis is a global problem and for 20 years had clinical pattern of involvement than the current one. This change, as well as increasing the number of reported cases may be associated with the onset of AIDS (1).

This disease is an infection that has as its primary etiologic agent Mycobacterium tuberculosis. This body has the sole natural reservoir, the human body (3) and is transmitted via airborne particles contaminated by various sizes, released into the air by talking, coughing or sneezing by a patient with contagious TB. It is an obligatory aerobic, so it most often affects the tissues with high oxygen tension region. Any body can be affected by the bacillus and extrapulmonary involvement is usually secondary to pulmonary involvement and may be difficult to diagnose (4).

Among the forms of involvement in extrapulmonary tuberculosis are the otolaryngological manifestations of this disease, mainly represented by cervical lymphadenopathy, laryngeal tuberculosis, tuberculous otitis media, Tuberculosis involvement of the nasal and oral cavity and oropharynx (5).

Poorer countries have a seven times greater incidence of tuberculosis than rich countries (1). With respect to individual factors, situations that favor the emergence of tuberculosis are: HIV infection, illness from measles, malnutrition, chronic alcoholism and use of immunosuppressive drugs (1).

According to data from the health ministry, the Amazon is the state with the second highest number of tuberculosis cases in Brazil, losing only to the state of Rio de Janeiro. Only in 2003 were recorded by the Office Cardoso Fontes 1.540 new cases of tuberculosis in the city of Manaus, which explains the best interest of deepening the knowledge on this subject.

The most common form of extrapulmonary tuberculosis involvement in head and neck is cervical lymphadenopathy. The disease can also affect other sites such as the middle ear, nasal cavity, oropharynx, nasopharynx, parotid gland, esophagus, submandibular gland, palate, tongue, trachea, larynx, thyroglossal duct cyst and oral mucosa (9).

The presence of cervical lymphadenopathy is sometimes an isolated finding. Can occur by the introduction of bacilli through the tonsils, pharynx or dental foci, although the most common route is the lymphohematogenous a primary lung focus. Usually this kind of commitment is insidious, with gradual increase of lymph node, but there are cases of acute form. There is progress to caseation, fistulization may occur, with output of caseous material poor in bacilli, called scrofula (10).

The nasal tuberculosis is rare and usually secondary to pulmonary focus. Its most common seat portion anteroinferior nasal septum in the region of greatest confluence zone called arteriovenous Kisselbach (2). Anatomoclinical forms of nasal tuberculosis can occur as lupus, tuberculoma and form ulcerocaseosa with congested and nodular mucosa, the patient may cause nasal obstruction, purulent rhinorrhea or perforation of the quadrangular septal cartilage (10). Anterior rhinoscopy there is a pale mucosa, foul, and there may be perforation of the nasal septum, the diagnosis of tuberculosis can be established by nasal exudate smear and biopsy of the lesion (2).

Among the granulomatous diseases of the larynx, tuberculosis is the most common. It is estimated that the involvement of the larynx occurs around $1 \%$ of patients with pulmonary tuberculosis (7). A study in Denmark showed a prevalence of $0.8 \%$ of laryngeal involvement in patients with tuberculosis and those patients with laryngeal involvement, $100 \%$ had pulmonary tuberculosis (10). Laryngeal involvement can present in a diffuse and exudative lesions or a localized (tuberculoma or polypoid lesion) (11).

The posterior commissure of the larynx and the area interarytenoid often are the first sites of involvement. Peculiarly, tuberculosis rarely extends to the hypopharynx or the subglottic region, which does not happen with laryngeal cancer (12).

The most common site of involvement is the laryngeal vocal fold (50-70\%), followed by ventricular band (40-50\%) and the remaining 10-15\% may involve the epiglottis, aryepiglottic fold, arytenoids, posterior commissure and subglottis (7). Laryngeal involvement usually occurs as edematous lesion, which subsequently ulcer at the posterior commissure arytenoid, and is classically associated with extensive pulmonary tuberculous lesions (7). Predominates in males, with approximate ratio of male / female 9:1 (10). It is common feature of these lesions to severe pain that affects the supply. Other common manifestations are hoarseness, cough, hemoptysis, and dysphagia (2).

The involvement of the oral cavity and oropharynx is rare. May be primary, which is very rare, as there is a need to break the integrity of the oral mucosa for Mycobacterium tuberculosisinstall himself. Another way is secondary to pulmonary tuberculosis by hematogenous dissemination or by self-inoculation of bronchial secretions (15). 
The oral lesions secondary to pulmonary tuberculosis may appear as ulcerations that can vary and morphology are very painful, with jagged edges, shallow or deep, with a tendency to progressive growth and the emergence of regional lymph nodes confluent. Another injury takes the form of lupus, which manifests itself as round nodules in the mucosa in groups, not painful. Involves mainly the tongue, lips, soft and hard palate and the dental alveoli, and the language the most common site (11).

The involvement of the middle ear is the second of tuberculous etiology ENT disease most often seen by the otolaryngologist, but it is believed that its incidence is higher because there are a large number of undiagnosed cases. The tuberculous otitis media (TOM) is most common routes of infection via the Eustachian tube and hematogenous, being the second most common (9).

The WTO usually manifests itself as a chronic otitis with otorrhea prolonged and resistant to medical treatment, which at first is watery and weak, but then becomes profuse, thick and purulent, and characteristically occurs painlessly. May be accompanied by conductive hearing loss early and profound increase in peri-auricular lymph nodes. The otoscopic examination may reveal thickening and, eventually, bulging tympanic membrane with loss of reference points, and may evolve into perforated eardrum can be multiple or single, accompanied by purulent otorrhea (9).

Some complications of the WTO are retroauricular fistula, facial paralysis, labyrinthitis, acute mastoiditis and osteomyelitis $(10,16)$. The facial palsy due to tuberculosis was documented in approximately $21 \%$ of patients with chronic tuberculous otitis media $(10,17)$. The prevalence of tuberculous otitis media in patients with pulmonary tuberculosis in different studies varies between 1 and $8.5 \%$ (13).

The criteria for diagnosis of tuberculous otitis media are: chronic otitis media unresponsive to antibiotics; hearing important driving, presence of large amounts of granulation tissue in the middle ear, facial paralysis, history of pulmonary tuberculosis, tuberculin skin test (PPD) positive; and regional lymphadenitis. The existence of three of these signals leads to the suspicion of the diagnosis. Have five or more, lead us to the diagnosis (14).

Considering the aspects mentioned above, the authors determined for this study to estimate the frequency of ENT manifestations in patients with tuberculosis treated in outpatient Araujo Lima, School of Medicine, Federal University of Amazonas, in Manaus, from the period July 2005 to June 2006, and analyze the behavior of the disease in this group. The present study has the following objectives:
1. Describe the frequency of different ENT manifestations occurred in the sample;

2. Correlate the data with the findings of the study described in the literature;

3. Analyze the behavior of the disease in this population.

\section{Method}

This was a descriptive cross-sectional in that patients diagnosed with pulmonary tuberculosis by sputum examination by the Department of Pulmonology at a university hospital, the period between July 2005 and June 2006, were referred to the Otolaryngology Department of the same hospital. These patients were then subjected to an ENT examination including anterior rhinoscopy, otoscopy, oroscopy and indirect laryngoscopy, and according to the complaints, additional tests would be required for diagnostic, according to the routine of the Otorhinolaryngology Clinic of Lima Araújo such as nasal endoscopy, fibrolaringoscopia, computed tomography of the ear and mastoid, tonal and vocal, among others.

This study comprised only patients diagnosed with pulmonary tuberculosis by the department of Pulmonology of the hospital, who had smear-positive, which when treated were submitted to anamnesis, physical examination and when necessary exams, according to the routine of specialized services and with at most two weeks of treatment.

The exclusion criteria of the study were treatment time exceeding two weeks, patients who did not attend ENT examination and patients who have negative sputum examination.

The data were analyzed are ENT symptoms reported by the patient, identified findings on otoscopy, rhinoscopy, oral examination, in addition to age, color, sex of patients and progression of the disease. The results were recorded on a protocol developed for the study.

The study was conducted according to the following steps:

1. Care for the patient and complete the protocol (schedule attached).

2. Compilation of data on patient care.

3. Statistical analysis of data, using Epi Info.

4. Analysis of the disease in our sample, from the statistical results found.

5. Comparison of the obtained data with those reported in the literature.

6. Conclusion.

Altogether, the 22 patients diagnosed with 


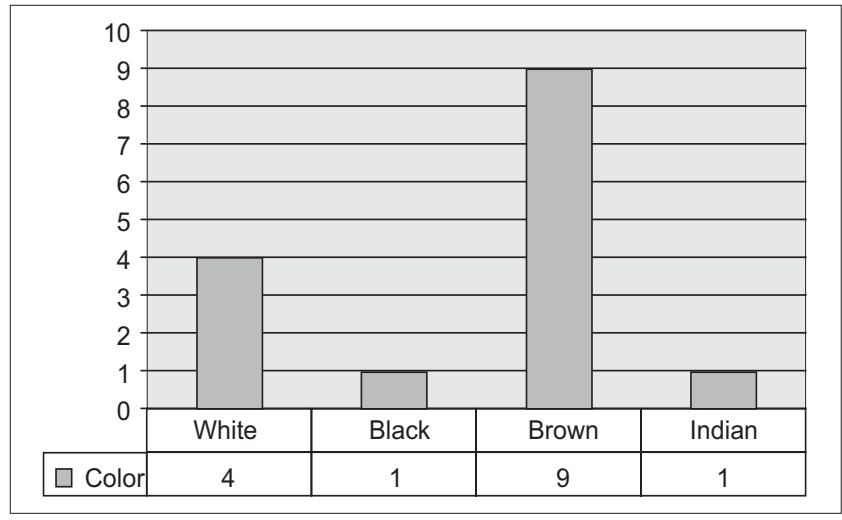

Graphic 1. Distribution of sample according to the color. Source: Souza, Renato et al, 2010.

pulmonary tuberculosis confirmed by sputum microscopy and 15 were seen at the otorhinolaryngology, referred by a pulmonology. Held questioning about symptoms and physical examination described above.

\section{RESULTS}

During the period from July 2005 to May 2006 sought phthisiology service, the outpatient department, and twenty-two patients with pulmonary tuberculosis confirmed by sputum smear. These patients were then referred to the otorhinolaryngology and attended only fifteen, and the other patients who did not attend the ENT examination, excluded from the study. The age of the patients were analyzed in the study ranged from 21 to 89 years.

The results are presented below in graphs.

Regarding gender, the frequency in males and females in the study sample was similar; seven patients were male and eight being female.

All patients were native of the Amazon, being fourteen of these coming from Manaus / AM and only one from the interior of Amazonas, municipality of Parintins, which is of indigenous ethnicity.

Regarding color, in this sample the majority of patients were brown (nine), four were white, one black and one patient was Indian (Graphic 1).

Most patients were between the third and sixth decade of life, being divided as follows: four in the third decade (26.7\%), three in the fourth decade (20\%), three in the fifth decade (20\%), two, sixth decade (13.3\%) and in the seventh, eighth and ninth decades there was only one patient each (6.7\%) (Graphic 2).

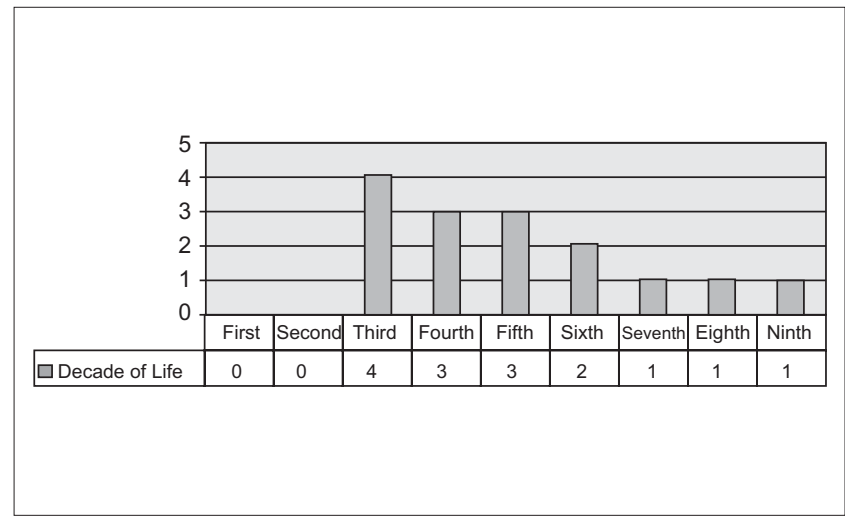

Graphic 2. Sample distribution according to age. Source: Souza, Renato et al, 2010.

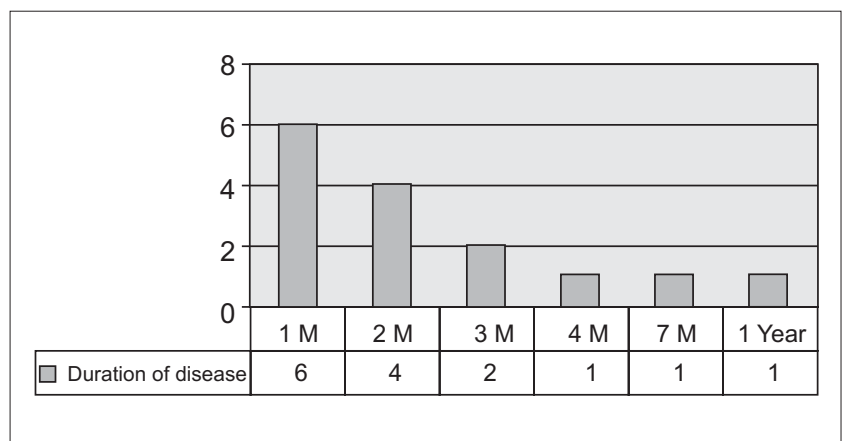

Graphic 3. Distribution of sample according to the time of disease progression. Source: Souza, Renato et al, 2010.

As for the duration of disease, most patients had respiratory symptoms for nearly a month (6 patients). Four reported complaints started two months ago, two three months ago and the remainder was divided into four months, seven months and one year. There is no way to prove whether these patients with symptoms had already drawn much really symptoms of tuberculosis or other entity that may have then been followed by an infection with TB (Graphic 3).

Among the patients, four reported being smokers and eleven denied using of tobacco.

Only one patient had co-infection with HIV and does not present any type of ENT manifestations of the disease (Graphic 4).

ENT manifestations in pulmonary tuberculosis, the main objective of our study were observed in only two of fifteen patients, accounting for $13.3 \%$ of the sample. This result was expected, since several bibliographies cite the rarity of this type of commitment (Graphic 5).

Among the 15 patients in the study, five showed abnormal ENT, but only two resulting from tuberculosis: 


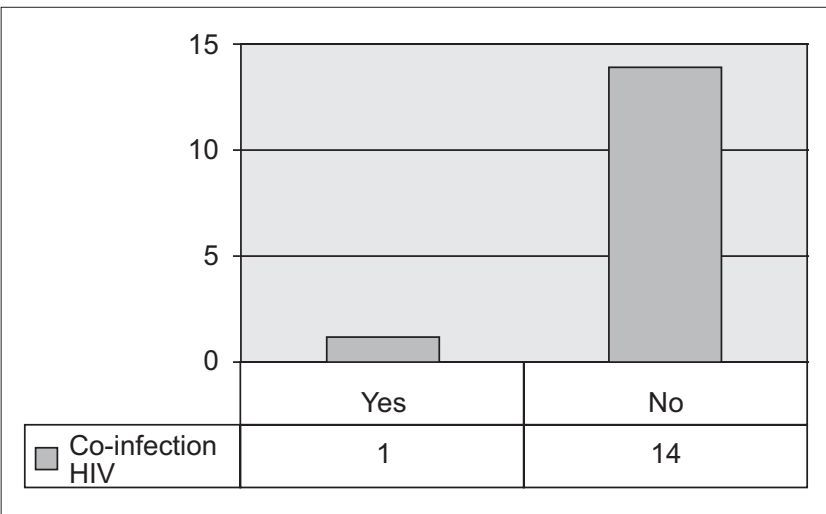

Graphic 4. Presence of co-infection with HIV among patients in the study. Source: Souza, Renato et al, 2010.

tuberculous otitis media (TOM), featuring five criteria (chronic otitis media unresponsive to antibiotics, driving significant hearing loss, history of pulmonary tuberculosis, TST positive and regional lymphadenitis) and lymph node tuberculosis (TB lymph nodes). Two patients had reflux disease pharyngolaryngeal after starting treatment for tuberculosis (Graphic 6).

\section{DISCUSSION}

The sample comprised 15 patients diagnosed with pulmonary tuberculosis confirmed by smear. A profile of patients registering data as age, sex, color, presence of comorbidities such as HIV infection, such as smoking habits.

The distribution by sex was balanced, with eight women and seven men. In work done by Boffo et al, published in 2004 on the association between AIDS and tuberculosis, was found a male / female ratio with a predominance of men. Perhaps a combination of social and biological factors is responsible for this relationship, which determines physiological distinctions, different behaviors, expectations and activities that exist in a social, economic and cultural. In our study, however, this justification does not apply since there was a similar distribution by sex. In the bibliographic sources consulted, were not found much information on the prevalence of TB in relation to sex.

Most patients were light brown, second appearance of the subjects was white, then a black and an Indian. This color distribution with predominance of browns can be explained by the characteristic of the people of our region. Worldwide, the prevalence of tuberculosis among blacks is twice that in whites (18). Prevalence rates are highest in Africa, but more important than the relationship with ethnicity, can be given its relationship with the

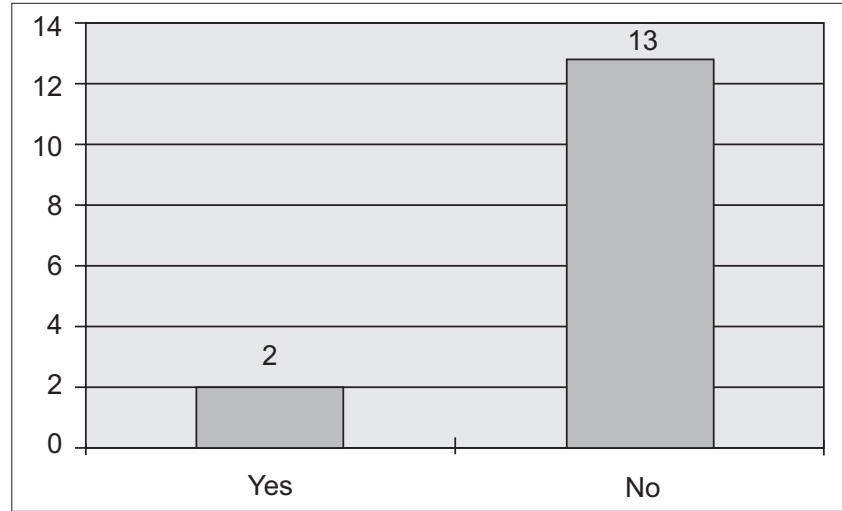

Graphic 5. Frequency of ENT manifestations in patients with pulmonary TB. Source: Souza, Renato et al, 2010.

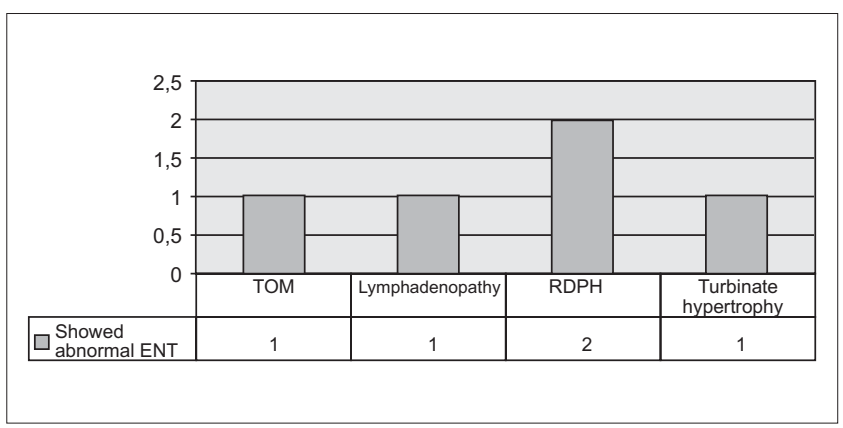

Graphic 6. Types of ENT manifestations in patients of the sample. Source: Souza, Renato et al, 2010.

socioeconomic conditions of the African continent, since the literature brings that tuberculosis is a disease that is prevalent in communities with poor living conditions.

According to age, most patients were between the third and fifth decades of life (10 patients). Literature data refer to a concentration of cases in the range between 20 and 49 years of age, which is consistent with findings in our study. It has been a decline of the disease on all tracks, with the largest fall in the range of 0-4 years, probably related to BCG. The lowest relative reduction was in the range of 60 years and over (8).

Concerning the time of evolution, most complained of symptoms pulmonary about a month. This is the average time from which patients come to seek medical care, to establish that there was no improvement in the daily fever, cough, fatigue and others. Three of the fifteen patients in the sample, sought treatment a long time after onset of symptoms. There is no need to actually start the respiratory symptoms. It is believed that these patients with development, for example, one year, to present other types of illness, with respiratory symptoms and after some time, then yes, they came active TB. Regarding the time 
of disease progression is important to mention that the otorhinolaryngological manifestations occur in active pulmonary tuberculosis, before the use of antibiotics for treatment (18).

Only one patient had co-infection with HIV. Many bibliographic sources bring the issue of the association between tuberculosis and HIV infection. According to the World Health Organization (WHO) in 1994, more than 16 million adults and one million children were infected with HIV. Of these, about 5.6 million were also infected with $M$. tuberculosis. Much evidence suggests that co-infection with HIV and M. tuberculosis is responsible for the increased incidence of tuberculosis in various parts of the world.

Before the advent of tuberculosis treatment with antibiotics currently used to this, patients with active pulmonary tuberculosis, developed often ENT manifestations, which could be laryngeal, ear, nose and sinuses. After the advent of tuberculosis treatment regimen with the RIP, the incidence of such involvement has decreased significantly. Currently, tuberculosis ENT is less than $5 \%$ of cases of extrapulmonary tuberculosis. In our study, the prevalence of ENT manifestations was slightly higher than that found in other studies, being $13,33 \%$. Only two patients, a total of 15 present, one tuberculous otitis media and other cervical lymphadenopathy. In a study by Pinho, 2003, reported that tuberculous otitis media is an uncommon disease, but when it occurs, causes a significant morbidity. There are indications that their frequency is actually higher than estimated, with a large number of undiagnosed cases, either no suspicion or difficulty in confirming the etiology. The presence of cervical lymphadenopathy is sometimes an isolated finding. Can occur by the introduction of bacilli through the tonsils, pharynx or dental foci, although the most common route is the lympho-hematogenous a pulmonary focus (2).

An interesting finding of our study was that two patients after early treatment have reported complaints consistent with those presented by patients with reflux pharyngolaryngeal. They state that prior to the disease, showed no such symptoms.

\section{CONCLUSION}

The sample comprised 15 patients diagnosed with pulmonary tuberculosis confirmed by smear. All patients underwent anamnesis and ENT examination.

Sample distribution according to sex was as follows: eight females and seven males. The merits, almost all were from Manaus, except one, resident in Parintins. Most consisted of mixed race ( 9 patients). The rest of the sample was composed of whites, blacks and Indians. Ten patients were between the $3 \mathrm{rd}$ and 5 th decades of life. There were only two in the sixth and one in the seventh, eighth and ninth.

Almost half the patients reported pulmonary symptoms for about a month. Other reported well over a frame dragging, arriving at the evolution of a year. The latter, probably could have made another disease before they become ill with tuberculosis.

Most patients denied use of tobacco (73\%) and only one had co-infection with HIV.

The prevalence of ENT manifestations was 13,33\%. One patient was afflicted with tuberculosis otitis media and other with cervical lymphadenophaty. In addition, two patients reported reflux pharyngolaryngeal after initiation of TB treatment and one patient had turbinate hypertrophy, with no correlation with the disease.

Being a rare type of involvement in TB patients, there are few studies on this topic. This study confirms the low frequency of ENT manifestations and show that despite regional differences as a lifestyle, socio-economic, racial and other factors, the results are similar to those observed in other studies in Brazil and worldwide.

\section{BibliograpHICAL REFERENCES}

1. Pinto AM, et al. Controle da Tuberculose: Uma Proposta de Integração Ensino-Serviço. $5^{a}$. ed. Rio de Janeiro: FUNASA/ CRPHF/SBPT. 2002. 236 p.

2. Martins AG, et al. Manifestações Otorrinolaringológicas da Tuberculose. Rev Bras Otorrinol. 2000, 66(6):666-671.

3. Goldman L, Bennett JC, et al. Cecil, Tratado de Medicina Interna. Rio de Janeiro: Guanabara Koogan. 2001.

4. Kasper DL, et al. Harrison'S, Principles of Internal Medicine. New York: McGraw-Hill. 2004.

5. Hungria H. Otorrinolaringologia. Rio de Janeiro: Guanabara Koogan. 2000.

6. Veronesi R, Focaccia R. Tratado de Infectologia. São Paulo: Atheneu. 2004.

7. Garcia RID, Cecatto SB, Rapoport PB, et al. Tuberculose e blastomicose laríngea: relato de três casos e revisão de literatura. Rev Bras Otorrinol. 2004, 70(2):255-259.

8. Lopes Filho O, Campos CA. Tratado de Otorrinolaringologia. São Paulo: Roca. 1994. 
9. Pinho MM, Kós AOA. Otite Média Tuberculosa, Artigo de Revisão. Rev Bras Otorrinol. 2003, 68(5):829-837.

10. Galietti F, et al. Examination of 41 cases of laryngeal tuberculosis observed between 1975-1985. Eur Respir J. 1989, 2(8):731-2.

11. Windle-Taylor P, Bailey CM. Tuberculous otitis media: a series of 22 patients. Laryngoscope. 1980, 90: 1039-1044.

12. Becker W, Naumann HH, Pfaltz CR. Ear, Nose and Throat Diseases. 2ª . ed. New York: Thieme, 1994; p.331-332.

13. Barrionuevo CE, Bayer E, Mais E. Otite Média Tuberculosa, Estado Atual. Rev. Bras. Otorrinol. 1991, 57(2):61-64.

14. Bento RF, Miniti A, Marone SAM. Tratado de Otologia.
São Paulo: Editora da Universidade de São Paulo, 1998; p.207209.

15. Miniti A, Bento RF, Butugan O. Otorrinolaringologia Clínica e Cirúrgica. São Paulo: Atheneu, 1993; p.203.

16. Boffo MMS. et al. Tuberculose associada à AIDS: características demográficas, clínicas e laboratoriais de pacientes atendidos em um serviço de referência do sul do Brasil. Jorn. Bras. Pneumo. 2004, 30(2):140-146.

17. Farrugia EJ, Raia SA, Phillipps JJ. Tuberculous otitis media - a case report. J Laringol Oto. 1997, 111:58-59.

18. Stead WW et al. Racial differences in susceptibility to infection by Micobacterium tuberculosis. N Engl J Med. 1990, 332:422-427. 